\title{
Prevalence of abdominal obesity in Abia State, Nigeria: results of a population-based house-to-house survey
}

This article was published in the following Dove Press journal: Diabetes, Metabolic Syndrome and Obesity:Targets and Therapy 31 July 2013

Number of times this article has been viewed

Innocent ljezie

Chukwuonye'

Abali Chuku²

Ugochukwu Uchenna

Onyeonoro ${ }^{3}$

Ikechi Gareth Okpechi ${ }^{4}$

Okechukwu Ojoemelam

Madukwe ${ }^{5}$

Theophilus Ifeanyichukwu

Umeizudike 6

Okechukwu Samuel Ogah ${ }^{7,8}$

'Department of Internal Medicine, ${ }^{2}$ Department of Ophthalmology,

${ }^{3}$ Department of Community Medicine,

Federal Medical Centre, Umuahia,

Nigeria; ${ }^{4}$ Division of Hypertension and Nephrology, University of Cape Town,

Cape Town, South Africa; ${ }^{5}$ Ministry

of Health, Nnamdi Azikiwe Secretariat,

Umuahia, Nigeria; ${ }^{6}$ Department

of Internal Medicine, Lagos State

University Teaching Hospital, Lagos,

Nigeria; ${ }^{7}$ Division of Cardiovascular

Medicine, University College Hospital,

Ibadan, Nigeria; ${ }^{8}$ Office of the

Commissioner for Health, Abia State

Ministry of Health, Umuahia, Nigeria

Correspondence: Okechukwu S Ogah Ministry of Health, Nnamdi Azikiwe Secretariat, PMB 7215, Umuahia,

Abia, Nigeria

Tel +234806774 7I2।

Fax +I 2159756817

Email osogah56156@yahoo.com
Background and objective: Abdominal obesity is associated with the risk of developing disorders, such as diabetes and hypertension. The objective of this study was to investigate the prevalence of abdominal obesity in Abia State, Nigeria.

Materials and methods: We carried out a cross-sectional study aimed at ascertaining the prevalence of abdominal obesity in Abia State, Nigeria. Participants in the study were recruited from communities in the three senatorial zones in the state. Screening for abdominal obesity was carried out in these subjects using waist circumference (the National Cholesterol Education Program Third Adult Treatment Panel criteria were used). The World Health Organization Stepwise Approach to Surveillance of chronic disease risk factors was used. Body mass index, anthropometric measurements, and other relevant data were also collected.

Results: Data on waist circumference were obtained from 2,807 subjects. The prevalence of obesity using body mass index in the population was $11.12 \%$. In men and women, it was $7.73 \%$, and $14.37 \%$, respectively. The prevalence of abdominal obesity in the population was $21.75 \%$. In men and women, it was $3.2 \%$ and $39.2 \%$, respectively.

Conclusion: The prevalence of abdominal obesity is high in Nigeria, and needs to be monitored because it is associated with increased cardiovascular risk.

Keywords: waist circumference, body mass index, central obesity

\section{Introduction}

Noncommunicable diseases (NCDs) such as diabetes mellitus, stroke, cancer, and cardiovascular disease are a major public health concern in Nigeria and subSaharan Africa. NCDs have overtaken communicable diseases as the leading causes of morbidity and mortality in the country. The changing disease pattern has been traditionally attributed to recent advances in medicine resulting in the development of drugs and vaccines for the effective control of communicable diseases. Other factors driving this transition include changes in diet, cigarette smoking, alcohol consumption, and inadequate exercise. ${ }^{1}$ A key modifiable risk factor for NCDs is overweight and obesity, highlighting the need for policy to reduce prevalence rates of overweight and obesity in order to help reduce the rising levels of NCDs.

Traditionally, obesity is usually defined as body mass index (BMI) of $30 \mathrm{~kg} / \mathrm{m}^{2}$ or more, according to World Health Organization criteria. ${ }^{2}$ Another common method of defining obesity is by using waist-circumference (WC) measurements. Obesity defined by WC is known as abdominal/central obesity. It is due to excessive abdominal fat around the stomach and abdomen. There are several cutoff criteria for abdominal obesity using the WC; however, the major ones include the National Cholesterol Education 
Program Third Adult Treatment Panel (NCEP-ATP III) ${ }^{3}$ (male $\geq 102 \mathrm{~cm}$, female $\geq 88 \mathrm{~cm}$ ) and the International Diabetes Federation ${ }^{4}$ (male $\geq 94 \mathrm{~cm}$, female $\geq 80 \mathrm{~cm}$ ). Obesity is assuming an epidemic dimension globally. Currently, more than 1 billion adults are overweight, and at least 300 million of them are clinically obese. In Nigeria, the prevalence range of being overweight is $20.3 \%-35.1 \%$, while the prevalence range of obesity is $8.1 \%-22.2 \%$ using the BMI definition. ${ }^{1}$ The prevalence rate of overweight and obesity in Nigeria is high, and there is a need for all concerned to pay a close attention to the menace.

Studies have shown that increased WC in patients with normal BMI is associated with higher levels of cardiovascular risk factors. ${ }^{5,6}$ Surveys have also shown that WC is more closely associated to all-cause mortality or cardiovascular risk factors than BMI. ${ }^{7-9}$ WCs above normal value are more of a risk factor for metabolic syndrome than BMI, ${ }^{10}$ and weighted evidence indicates that WC coupled with BMI predicts health risk better than BMI alone. ${ }^{8}$ These studies highlight the need to measure the WC of subjects in addition to their BMI in all cases.

There are studies that have been carried out on prevalence of abdominal obesity in Nigeria using the ATP III criterion; however, most are hospital-based studies. ${ }^{11-13}$ In addition, in Abia State, in Nigeria's southeastern region, there is no published study on abdominal obesity. These facts prompted us to embark on this study.

\section{Materials and methods}

This was a cross-sectional study carried out in randomly selected urban and rural communities in Abia State, southeastern Nigeria. The state has a population of 3,152,691 inhabitants. It is traditionally divided into three senatorial zones and 17 local government areas (LGAs), and has 291 political wards. It is largely inhabited by the Igbo people (one of the three major ethnic groups in Nigeria). The state's economy depends mainly on agriculture and commerce, the latter contributing about $27 \%$ to the state's gross domestic product.

The study population comprised adults (18 years old and above) who were residing in the state. Individuals in transit or on temporary visits were excluded from the study. Pregnant women, women in puerperium (up to 6 weeks postdelivery), subjects with ascites, subjects with bloated abdomen from gaseous distension (confirmed by percussion), and those with malignancies were excluded from the study.

The calculated minimum sample size for the survey was 2,880. It was a cross-sectional observational study. A multistage stratified sampling method was used to randomly select the study participants from the three senatorial zones and 17 LGAs in the state. The three senatorial zones include: Abia North, Abia Central and Abia South. One rural and one urban LGA were randomly selected from each senatorial zone. They were Ohafia and Isuikwuato/Bende for Abia North, Umuahia North and Ikwuano for Abia Central, and Aba South and Ukwa East for Abia South senatorial zones. In each LGA, four enumeration areas (EAs) were randomly selected from the listing of all the EAs. Households in these EAs were further listed and eligible participants were selected. The selection was such that not more than two eligible participants of either sex were selected from each household. Using the EA map and starting from a prominent landmark in the community (a church, a school, etc), trained interviewers proceeded from household to household, interviewing eligible listed respondents until a minimum of 120 respondents were interviewed in the community. A modified World Health Organization Stepwise Approach to Surveillance questionnaire was used for data collection. ${ }^{14}$ The trained health workers comprised six interviewers (doctors, nurses, and other health workers), and each team had a consultant physician (community physician/internal medicine) as a supervisor. Information collected included such sociodemographic parameters as sex, age, use of alcohol and tobacco, and dietary information on consumption of fruits and vegetables. Other data recorded included personal history and family history of chronic NCDs, such as hypertension, diabetes, and awareness of common NCDs and physical activity.

Ethical approval for the survey was obtained from the Abia State Ministry of Health. Participation in the survey was voluntary, and written consent was obtained from participants prior to enrolment after due explanation of the purpose, objectives, benefits, and risks of the survey.

\section{Anthropometry and blood-pressure measurement}

The subjects had their blood pressure, height, and weight measured. Both systolic and diastolic blood pressures were measured thrice in a sitting position using an Omron M2 upper-arm blood-pressure monitor (Omron Healthcare, Kyoto, Japan), appropriate cuff size, and after a 5-minute rest. Three blood-pressure readings were taken at an interval of 2 minutes. Thereafter the average blood pressure for the second and third readings (systolic/diastolic) was averaged. Using a stadiometer, respondents' height was measured in centimeters, while their weight was measured using a weighing scale in kilograms, from which the BMI was determined. The WC of the subjects was also determined. 


\section{Definition of terms}

\section{Waist circumference}

WC was measured using a nonstretchable fiber measuring tape. The participants were asked to stand erect in a relaxed position with both feet together on a flat surface; one layer of clothing was allowed. It was measured to the nearest $0.5 \mathrm{~cm}$ at the high point of the iliac crest at minimal respiration.

\section{Abdominal obesity}

Abdominal obesity was defined as a WC of $102 \mathrm{~cm}$ or more in men and $88 \mathrm{~cm}$ or more in women, based on the ATP III criteria. $^{3}$

\section{BMI}

BMI was measured with the WHO classification ${ }^{2}$ as follows: underweight BMI below $18.5 \mathrm{~kg} / \mathrm{m}^{2}$, normal weight $18.5-24.9 \mathrm{~kg} / \mathrm{m}^{2}$, and overweight BMI $25-29.9 \mathrm{~kg} / \mathrm{m}^{2}$. BMI of $30-34.9 \mathrm{~kg} / \mathrm{m}^{2}$ defines class I obesity, BMI of $35-39.9 \mathrm{~kg} / \mathrm{m}^{2}$ class II obesity, and BMI of $40 \mathrm{~kg} / \mathrm{m}^{2}$ and above was used to define class III obesity.

\section{Hypertension}

Subjects having systolic blood pressure $140 \mathrm{mmHg}$ and above or diastolic blood pressure $90 \mathrm{mmHg}$ and above or who had normal blood pressure but were pharmacologically being treated for hypertension were categorized as hypertensives. ${ }^{15,16}$

\section{Diabetes mellitus}

A history of previously known diabetes or a fasting plasma glucose of $126 \mathrm{mg} / \mathrm{dL}$ or more, and impaired fasting glucose defined as fasting plasma glucose of $100-125 \mathrm{mg} / \mathrm{dL}$ or a random blood glucose of $180 \mathrm{mg} / \mathrm{dL}$ or higher, was classified as diabetes mellitus, and impaired glucose tolerance was defined as random blood glucose between 140 and $180 \mathrm{mg} / \mathrm{dL} \cdot{ }^{17}$

\section{Statistical analysis}

Data obtained were entered using EpiData Software version 3.1 (EpiData Association, Odense, Denmark), while analysis was carried out using SPSS version 17.0 (IBM, Armonk, NY, USA). Relevant means and standard deviation were calculated for quantitative continuous variables, and qualitative variables were analyzed using proportions. Findings were presented using relevant frequency tables and appropriate charts. Risk factors of obesity and abdominal obesity were estimated using logistic regression analysis.

\section{Results}

Data were collected from 2,880 subjects; however, only 2,807 had their WC documented. The number of men was $1,378(49.09 \%)$, and the number of women participants 1,429 $(50.90 \%)$. The mean age of the men was $41.6 \pm 18.8$ years, while the mean age of the women was $42.3 \pm 18.5$ years. The $P$-value was significant. Mean WCs of the men and women, respectively, were $81.7 \pm 9.7$ and $85.7 \pm 12.8 \mathrm{~cm}$. Mean BMI in the men and women was $24.1 \pm 3.7$ and $25.2 \pm 5.1$, respectively. The $P$-value was significant. Five hundred and seventy-four (41.7\%) and $553(38.7 \%)$ of the men and women had hypertension, respectively. Twenty-six (3.3\%), and $30(3.5 \%)$ of the men and women had diabetes mellitus, respectively. See Table 1 for more details.

Table 2 shows age-specific prevalence of obesity and abdominal obesity classified by sex. In men, obesity and abdominal obesity appears more common in those in the age range of 35-44 years and above. However, obesity is

Table I Sociodemographic characteristics of respondents by sex

\begin{tabular}{|c|c|c|c|}
\hline Characteristics & $\begin{array}{l}\text { Men } \\
(n=1378)\end{array}$ & $\begin{array}{l}\text { Women } \\
(n=1429)\end{array}$ & $P$-value \\
\hline Mean age (years) & $41.6 \pm 18.4$ & $42.3 \pm 18.5$ & 0.281 \\
\hline Mean weight (kg) & $68.1 \pm 16.7$ & $63.3 \pm 14.2$ & $<0.0001$ \\
\hline Mean height (m) & $1.68 \pm 0.08$ & $1.58 \pm 0.08$ & $<0.0001$ \\
\hline Mean BMI & $24.6 \pm 3.7$ & $25.2 \pm 5.2$ & $<0.0001$ \\
\hline Mean heart rate & $75.2 \pm 11.7$ & $79.0 \pm 11.3$ & $<0.000$ I \\
\hline Mean SBP & $|36| \pm 20.4$. & $132.4 \pm 23.8$ & $<0.000$ I \\
\hline Mean DBP & $77.4 \pm 14.6$ & $76.3 \pm 16.8$ & \\
\hline $\begin{array}{l}\text { Mean waist } \\
\text { circumference }(\mathrm{cm})\end{array}$ & $81.7 \pm 9.7$ & $85.7 \pm 12.8$ & $<0.0001$ \\
\hline $\begin{array}{l}\text { Mean hip } \\
\text { circumference }(\mathrm{cm})\end{array}$ & $91.9 \pm 9.7$ & $95.7 \pm 12.8$ & $<0.0001$ \\
\hline \multicolumn{4}{|l|}{ Education } \\
\hline $\begin{array}{l}\text { Secondary } \\
\text { and above }\end{array}$ & 1029 (94.4\%) & $953(82.0 \%)$ & \\
\hline$<$ Secondary & $61(5.6 \%)$ & 209 (18.0\%) & \\
\hline \multicolumn{4}{|l|}{ Annual income } \\
\hline$\leq \mathbb{N 1 0 0 , 0 0 0}$ & 399 (39.8\%) & $54 I(60.6 \%)$ & \\
\hline$\geq N \mid 00,000$ & $604(60.2 \%)$ & $352(39.4 \%)$ & \\
\hline \multicolumn{4}{|l|}{ Marital status } \\
\hline Single & $754(55.2 \%)$ & $842(59.2 \%)$ & \\
\hline Married & 617 (44.8\%) & $580(40.8 \%)$ & \\
\hline Ever smoked & $358(26.0 \%)$ & 14 (1.0\%) & \\
\hline Current smokers & $368(26.7 \%)$ & 15 (I.1\%) & \\
\hline $\begin{array}{l}\text { Family history of } \\
\text { diabetes mellitus }\end{array}$ & 142 (I0.3\%) & 136 (9.6\%) & \\
\hline Diabetes mellitus & $26(3.3 \%)$ & 30 (3.5\%) & \\
\hline $\begin{array}{l}\text { Family history of } \\
\text { hypertension }\end{array}$ & 340 (20.48\%) & $288(20.4 \%)$ & \\
\hline Hypertension & $574(41.7 \%)$ & $553(38.7 \%)$ & \\
\hline
\end{tabular}

Notes: $\#$ is Nigerian naira, US\$I = \#155.

Abbreviations: BMI, body mass index; SBP, systolic blood pressure; DBP, diastolic blood pressure. 
Table 2 The distribution of obesity (defined by BMI) and abdominal obesity (defined by WC) according to age and sex

\begin{tabular}{|c|c|c|c|c|c|c|c|c|}
\hline Age-group (years) & $<24$ & $25-34$ & $35-44$ & $45-54$ & $55-64$ & $\geq 65$ & $\chi^{2}$ & $P$-value \\
\hline \multicolumn{9}{|l|}{ Men } \\
\hline Obesity (BMI) & $n=220$ & $n=304$ & $n=186$ & $n=160$ & $n=124$ & $n=183$ & 115.9 & $<0.001$ \\
\hline Underweight (\%) & $6(2.7)$ & $2(7)$ & $2(1.1)$ & $2(1.3)$ & $5(4.0)$ & $14(7.7)$ & & \\
\hline Normal (\%) & $185(84.1)$ & $192(63.2)$ & $93(50)$ & $88(55.0)$ & $55(4 I .0)$ & $110(60.1)$ & & \\
\hline Overweight (\%) & $24(10.9)$ & $92(30.3)$ & $70(37.6)$ & $51(31.9)$ & $5 I(4 I . I)$ & $47(25.7)$ & & \\
\hline Obese (\%) & $5(2.3)$ & $18(5.9)$ & $21(11.3)$ & $19(11.9)$ & $16(12.9)$ & $12(66.6)$ & & \\
\hline Obesity (WC) & $n=269$ & $n=358$ & $n=214$ & $n=187$ & $n=140$ & $n=203$ & $30.7 I$ & $<0.001$ \\
\hline No & $269(100.0)$ & $355(99.2)$ & $206(96.3)$ & $176(94.1)$ & 130 (92.9) & $192(94.6)$ & & \\
\hline Yes & $0(0)$ & $3(0.8)$ & $8(3.7)$ & II (5.9) & $10(7.1)$ & II (5.4) & & \\
\hline \multicolumn{9}{|l|}{ Women } \\
\hline Obesity (BMI) & $n=230$ & $n=306$ & $n=184$ & $n=178$ & $n=138$ & $n=189$ & 83.69 & $<0.001$ \\
\hline Underweight (\%) & $6(2.6)$ & $5(1.6)$ & $\mathrm{I}(0.5)$ & $2(1.1)$ & $4(2.9)$ & II (5.8) & & \\
\hline Normal (\%) & I64 (7I.3) & $162(52.9)$ & $72(39.1)$ & $85(47.8)$ & $68(49.3)$ & $110(58.2)$ & & \\
\hline Overweight (\%) & $50(21.7)$ & $89(29.1)$ & $61(33.2)$ & $56(31.5)$ & $37(26.8)$ & $46(24.3)$ & & \\
\hline Obese (\%) & $10(4.3)$ & $50(16.3)$ & $30(27.2)$ & $35(19.7)$ & $29(21.0)$ & $22(11.6)$ & & \\
\hline Obesity (WC) & $n=259$ & $n=346$ & $n=218$ & $n=213$ & $n=159$ & $n=213$ & 95.0 & $<0.001$ \\
\hline No & $212(81.9)$ & $234(67.6)$ & $103(47.2)$ & $104(48.8)$ & $77(48.8)$ & $126(59.2)$ & & \\
\hline Yes & 47 (18.1) & $112(32.4)$ & II 5 (52.8) & $109(5 \mathrm{I} .2)$ & $82(51.6)$ & $87(40.8)$ & & \\
\hline
\end{tabular}

Abbreviations: BMI, body mass index; WC, waist circumference.

most common in the age range of 65 years and above, while abdominal obesity is most common in the 55- to 64-year age range. In women, obesity is more common in the age range of 35-44 years to 55-64 years. It is most common at the age range of 55-64 years. However, with regard to abdominal obesity, it is more common in the age range of 24-35 years and is most common at 45-54 and 55-64 years. Obesity and abdominal obesity declined at the age range of 65 years and above in women. The prevalence of overweight in men was $28.46 \%$; the prevalence in women was $27.67 \%$. The prevalence of overweight in the studied population (men and women) was $28.05 \%$. The prevalence of general obesity in the men was $7.73 \%$; in women, it was $14.37 \%$. The $P$-value was significant. The overall prevalence of obesity among the population was $11.12 \%$. The prevalence of abdominal obesity among the men was $3.2 \%$; prevalence of abdominal obesity in women was $39.21 \%$. The prevalence of abdominal obesity in the population (men and women) was $21.75 \%$.

Table 3 shows predictors of obesity in men and women in the study. It shows that men above the age of 35 years have about a twelvefold-higher risk of developing abdominal obesity than those below 35 years (odds ratio $[\mathrm{OR}]=12.6, P=0.002)$. In women, the increased risk is about double $(\mathrm{OR}=2.35, P<0.001)$. Risk of abdominal obesity increased with increasing educational status for both sexes, while higher education was found to be a significant risk factor among women only. Men who smoke tend to have a higher risk of developing abdominal obesity $(\mathrm{OR}=1.5$,
$P=0.284)$; however, in females this tends to be protective for obesity $(\mathrm{OR}=0.62, P=0.550)$ and abdominal obesity $(\mathrm{OR}=0.33, P=0.120)$ respectively. Being single, having a higher income ( $\geq \$ 100,000.00)$, and alcohol consumption were associated with lesser odds of being obese for both men and women.

\section{Discussion}

The prevalence of obesity was $11.12 \%$. This is in keeping with the prevalence range of obesity in Nigeria $(8.1 \%-22.2 \%)$ observed by Chukwuonye et $\mathrm{al}^{1}$ in a systematic review of literature published in Nigeria on obesity. The prevalence of abdominal obesity in Abia State, southeastern Nigeria, from this study was $21.75 \%$. The prevalence in men and women was $3.2 \%$, and $39.21 \%$, respectively. We compared our findings on abdominal obesity with similar studies carried out in Nigeria using the NCEP-ATP III criteria. Amole et $\mathrm{al}^{11}$ in southwestern Nigeria observed an overall prevalence of abdominal obesity of $33.8 \%$. The prevalence in men and women was $8.9 \%$ and $53.8 \%$, respectively. The prevalence in their study was higher than that observed in our study. This may have been due to the fact that their sample size was much smaller (400); in addition, it was a hospital-based study. In a study carried out in the eastern part of Nigeria by Ejim et a ${ }^{12}$ on cardiovascular risk factors in the middle-aged and elderly population, the overall prevalence of abdominal obesity was $31 \%$. The reason for the higher prevalence among this population could be that the study was carried out in middle-aged and elderly 
Table 3 Logistic regression analysis of risk factors of obesity and abdominal obesity by sex

\begin{tabular}{|c|c|c|c|c|}
\hline & \multicolumn{2}{|l|}{ Men } & \multicolumn{2}{|l|}{ Women } \\
\hline & Obesity & Abdominal obesity & Obesity & Abdominal obesity \\
\hline \multicolumn{5}{|c|}{ Age-groups (years) } \\
\hline - $<35$ & 1 & 1 & 1 & 1 \\
\hline \multirow[t]{2}{*}{ - $\geq 35$} & $1.79(0.96-3.34)^{*}$ & $12.6(2.4 \mid-60.35)^{*}$ & $1.53(1.04-2.26)^{*}$ & $2.35(1.67-3.32)^{*}$ \\
\hline & $P=0.069$ & $P=0.002$ & $P=0.032$ & $P=0.000$ \\
\hline \multicolumn{5}{|l|}{ Educational level } \\
\hline - None & 1 & 1 & 1 & 1 \\
\hline \multirow[t]{2}{*}{ - Primary } & $4.00(0.930-17.32)^{*}$ & $0.90(0.11-7.55)^{*}$ & $2.10(1.07-4.15)^{*}$ & $2.17(1.3 \mathrm{I}-3.58)^{*}$ \\
\hline & $P=0.063$ & $P=0.191$ & $P=0.032$ & $P=0.002$ \\
\hline \multirow[t]{2}{*}{ - Secondary } & $3.24(0.74-\mid 4.21)^{*}$ & $1.76(0.22-14.33)^{*}$ & $1.96(0.99-3.90)^{*}$ & $2.10(1.27-3.52)^{*}$ \\
\hline & $P=0.120$ & $P=0.596$ & $P=0.054$ & $P=0.005$ \\
\hline \multirow[t]{2}{*}{ - Tertiary } & $4.23(0.95-19.82)^{*}$ & $1.58(0.19-13.36)^{*}$ & $3.61(1.75-7.45)^{*}$ & $4.29(2.39-7.73)^{*}$ \\
\hline & $P=0.059$ & $P=0.68$ & $P=0.001$ & $P=0.000$ \\
\hline \multicolumn{5}{|l|}{ Smoking status } \\
\hline - No & 1 & 1 & I & 1 \\
\hline \multirow[t]{2}{*}{ - Yes } & $0.78(0.52-1.20)^{*}$ & $1.50(0.72-3.130)^{*}$ & $0.62(0.13-2.97)^{*}$ & $0.33(0.08-1.32)^{*}$ \\
\hline & $P=0.271$ & $P=0.284$ & $P=0.550$ & $P=0.12$ \\
\hline \multicolumn{5}{|l|}{ Marital status } \\
\hline - Married & 1 & 1 & I & I \\
\hline \multirow{2}{*}{ - Single } & $1.23(0.663-2.28)^{*}$ & $0.90(0.304-2.680)^{*}$ & $0.7 \mid(0.49-1.05)^{*}$ & $0.58(0.42-0.80)^{*}$ \\
\hline & $P=0.513$ & $P=0.853$ & $P=0.083$ & $P=0.001$ \\
\hline \multicolumn{5}{|c|}{ Alcohol consumption } \\
\hline - No & I & I & I & I \\
\hline \multirow[t]{2}{*}{ - Yes } & $1.36(0.834-2.229)^{*}$ & $1.07(0.452-2.514)^{*}$ & $0.65(0.47-0.90)^{*}$ & $0.64(0.48-0.86)^{*}$ \\
\hline & $P=0.22$ & $P=0.883$ & $P=0.009$ & $P=0.003$ \\
\hline \multicolumn{5}{|l|}{ Annual income } \\
\hline - $<\# \mid 00,000$ & 1 & 1 & I & 1 \\
\hline \multirow[t]{2}{*}{ - $\geq \# 100,000$} & $0.53(0.323-0.87)^{*}$ & $0.26 \mathrm{I}(0.10-0.7 \mathrm{I})^{*}$ & $0.74(0.52-1.05)^{*}$ & $0.78(0.57-1.06)^{*}$ \\
\hline & $P=0.011$ & $P=0.008$ & $P=0.092$ & $P=0.11$ \\
\hline
\end{tabular}

Notes: $*$ Odds ratio; US $\$ I=\$ 150$. is Nigerian naira.

subjects with much older mean age $(59.8 \pm 9.9$ years $)$. It is obvious from our study and other studies ${ }^{18}$ that the prevalence of abdominal obesity is high in this age-group. Iloh et al ${ }^{13}$ also had a higher prevalence rate in their study (50.6\%). Possible reasons include small sample size (122), the fact that it was a hospital-based study, and the fact that it was carried out on geriatrics. In this study, we also observed that the prevalence of abdominal obesity is much higher in women. In most studies carried out in the US and other parts of the world, prevalence among women is also higher. ${ }^{19-22}$ The reason for the higher prevalence may be that men engage in more strenuous activity than females. ${ }^{21}$ Moreover, more men are employed in our society, and a good number of the women are mainly housewives, with less activity to engage in.

In this study, the prevalence of abdominal obesity is higher than the prevalence of obesity. This has some health implications. It implies that some people not classified as obese based on the use of BMI are possibly at higher cardiovascular risk..$^{5-9}$
Logistic regression analysis (Table 3 ) shows that men above the age of 35 years are at about a twelvefold-higher risk of developing obesity than those below 35 years. This is in keeping with the fact that abdominal obesity increases with age, as observed in Table 2. Those with higher incomes were also noted to be at less risk of abdominal obesity. This may have to do with the fact that they can afford a more balanced diet than poorer members of the society. Obesity in some studies is known to decrease with income. ${ }^{23}$ Being single was noted to have decreased risk for abdominal obesity; the reason for this could be that the singles are much younger than the married subjects. In Nigeria, the unmarried are usually below 35 years. Table 2 also shows that those below this age-group have lower prevalence of obesity. Alcohol consumption tends to have lower risk of abdominal obesity in this study. Studies have shown that high alcohol intake is associated with higher WC and abdominal obesity. ${ }^{24}$ However, most of the participants that drink alcohol do so occasionally, and light alcohol drinking is known to be associated with lower incidence of obesity. ${ }^{25}$ 
Those that smoked were noted to have increased risk of abdominal obesity in our study. It is known that smoking is an increased risk factor for abdominal obesity. ${ }^{26}$ However, in women in this study, it tended to decrease the risk of abdominal obesity; this may have something to do with the very low number of women that smoke, and also to the fact that they seldom smoke.

\section{Conclusion}

This study has shown that the prevalence of abdominal obesity in Abia State, southeastern Nigeria, is high $21.75 \%$. Prevalence among women was also noted to be much higher than prevalence among men. Prevalence of abdominal obesity was also noted to be higher than prevalence observed for obesity; this shows that some subjects not classified as obese based on the BMI have abdominal obesity and are at increased cardiovascular risk. ${ }^{5-9}$ The study, therefore, points out the need to measure WC in subjects seen in hospitals in Nigeria and other parts of the world in addition to the BMI estimation. It also shows that there is a need for the various government agencies in Nigeria and sub-Saharan Africa charged with health care to intervene, in order to reduce the prevalence of abdominal obesity in the region.

\section{Acknowledgments}

The data used in this study were obtained from Abia State Ministry of Health survey on noncommunicable disease risk factors using the World Health Organization Stepwise Approach to Surveillance for chronic disease risk factors. The study was undertaken in 2011. It was pioneered by Dr Ogah OS (Honourable Commissioner for Health). The projected was supported financially by Health Systems Development Project II (World Bank-assisted).

\section{Disclosure}

The authors report no conflicts of interest in this work.

\section{References}

1. Chukwuonye II, Chuku A, John C, et al. Prevalence of overweight and obesity in adult Nigerians - a systematic review. Diabetes Metab Syndr Obes. 2013;6:43-47.

2. World Health Organization. Physical Status: The Use and Interpretation of Anthropometry. Geneva: WHO; 1995.

3. National Cholesterol Education Program (NCEP) Expert Panel on Detection, Evaluation, and Treatment of High Blood Cholesterol in Adults (Adult Treatment Panel III). Third Report of the National Cholesterol Education Program (NCEP) Expert Panel on Detection, Evaluation, and Treatment of High Blood Cholesterol in Adults (Adult Treatment Panel III) final report. Circulation. 2002;106:3143-3421.
4. Alberti KG, Eckel RH, Grundy SM, et al. Harmonizing the metabolic syndrome: a joint interim statement of the International Diabetes Federation Task Force on Epidemiology and Prevention; National Heart, Lung, and Blood Institute; American Heart Association; World Heart Federation; International Atherosclerosis Society; and International Association for the Study of Obesity. Circulation. 2009;120: 1640-1645.

5. Miyawaki T, Abe M, Yahata K, Kajiyama N, Katsuma H, Saito N. Contribution of visceral fat accumulation to the risk factors for atherosclerosis in non-obese Japanese. Intern Med. 2004;43:1138-1144.

6. Ito $\mathrm{H}$, Nakasuga $\mathrm{K}, \mathrm{Ohshima} \mathrm{A}$, et al. Excess accumulation of body fat is related to dyslipidemia in normal-weight subjects. Int $J$ Obes Relat Metab Disord. 2004;28:242-247.

7. Simpson JA, MacInnis RJ, Peeters A, Hopper JL, Giles GG, English DR. A comparison of adiposity measures as predictors of all-cause mortality: the Melbourne Collaborative Cohort Study. Obesity (Silver Spring). 2007;15:994-1003

8. Janssen I, Katzmarzyk PT, Ross R. Waist circumference and not body mass index explains obesity-related health risk. Am J Clin Nutr. 2004;79:379-384.

9. Stolk RP, Suriyawongpaisal P, Aekplakorn W, Woodward M, Neal B. Fat distribution is strongly associated with plasma glucose levels and diabetes in Thai adults - the InterASIA study. Diabetologia. 2005;48: 657-660.

10. Sidney CS Jr, David H. Abdominal obesity, waist circumference and cardiometabolic risk: awareness among primary care physicians, the general population and patients at risk - the Shape of the Nations survey. Curr Med Res Opin. 2007;23:379-384.

11. Amole IO, OlaOlorun AD, Odeigah LO, Adesina SA. The prevalence of abdominal obesity and hypertension amongst adults in Ogbomoso, Nigeria. Afr J Prim Health Care Fam Med. 2011;3:1-5.

12. Ejim EC, Okafor CI, Emehel A, et al. Prevalence of cardiovascular risk factors in the middle-aged and elderly population of a Nigerian rural community. J Trop Med. 2011;2011:308687.

13. Iloh G, Amadi AN, Njoku PU, Ofoedu JN, Awa-Madu J. The magnitude of abdominal adiposity and atherogenic dyslipidemia among geriatric Nigerians with arterial hypertension in a rural hospital in South-eastern Nigeria. Niger Clin Pract. 2012;15:462-468.

14. World Health Organization. WHO STEPS Surveillance Manual: The WHO STEP wise Approach to Chronic Disease Risk Factor Surveillance. Geneva: WHO; 2005. Available from: http://whqlibdoc.who.int/ publications/2005/9241593830_eng.pdf. Accessed June 9, 2013.

15. Hansson L, Hedner T, Himmelmann A. The 1999 WHO-ISH Guidelines for the Management of Hypertension - new targets, new treatment and a comprehensive approach to total cardiovascular risk reduction. Blood Press Suppl. 1999;1:3-5.

16. Chobanian AV, Bakris GL, Black HR, et al. Seventh report of the Joint National Committee on Prevention, Detection, Evaluation, and Treatment of High Blood Pressure. Hypertension. 2003;42: $1206-1252$.

17. World Health Organization. Definition, Diagnosis and Classification of Diabetes Mellitus and its Complications. Geneva: WHO; 1999.

18. Marques-Vidal P, Bochud M, MooserV,PaccaudF, WaeberVollenweider G. Prevalence of obesity and abdominal obesity in the Lausanne population. BMC Public Health. 2008;8:330.

19. Okosun IS, Prewitt TE, Cooper RS. Abdominal obesity in the United States: prevalence and attributable of hypertension. J Hum Hypertens. 1999; 13:425-430.

20. Olusi SO, Al-Awadi, Abraham M. Baseline population survey data on the prevalence of risk factors for coronary disease among Kuwaitis aged 15 years and older. Ann Saudi Med. 2003;23:162-166.

21. Regaeian M, Salem Z. Prevalence of obesity and abdominal obesity in a sample of urban adult population within South East of Iran. PakJ Med Sci. 2007;23:193-197.

22. Anoyo P, Loria A, Fernández V. Prevalence of pre-obesity and obesity in urban adult Mexican in comparison with other larger survey. Obes Res. 2000;8:179-185. 
23. Iowa Department of Public Health. Annual Report: Survey Results from the 2005 Iowa BRFSS. Des Moines: Iowa Department of Public Health; 2005.

24. Ryu M, Kimm H, Jo J, Lee SJ, Jee SH. Association between alcohol intake and abdominal obesity among the Korean population. Epidemiol Health. 2010;32:e2010007.

25. National Institute on Alcohol Abuse and Alcoholism. Drinking alcohol associated with Obesity. Drinking patterns affect body mass index [press release]. Bethesda (MD); February 24, 2005.
26. Saarni SE, Pietiläinen K, Kantonen S, Rissanen A, Kaprio J. Association of smoking in adolescence with abdominal obesity in adulthood: a follow-up study of 5 birth cohorts of Finnish twins. Am J Public Health. 2009;99:348-354.

\section{Publish your work in this journal}

Diabetes, Metabolic Syndrome and Obesity: Targets and Therapy is an international, peer-reviewed open-access journal committed to the rapid publication of the latest laboratory and clinical findings in the fields of diabetes, metabolic syndrome and obesity research. Original research, review, case reports, hypothesis formation, expert opinion and commentaries are all considered for publication. The manuscript management system is completely online and includes a very quick and fair peer-review system, which is all easy to use. Visit http://www.dovepress.com/testimonials.php to read real quotes from published authors.

Submit your manuscript here: http://www.dovepress.com/diabetes-metabolic-syndrome-and-obesity-targets-and-therapy-journal 